
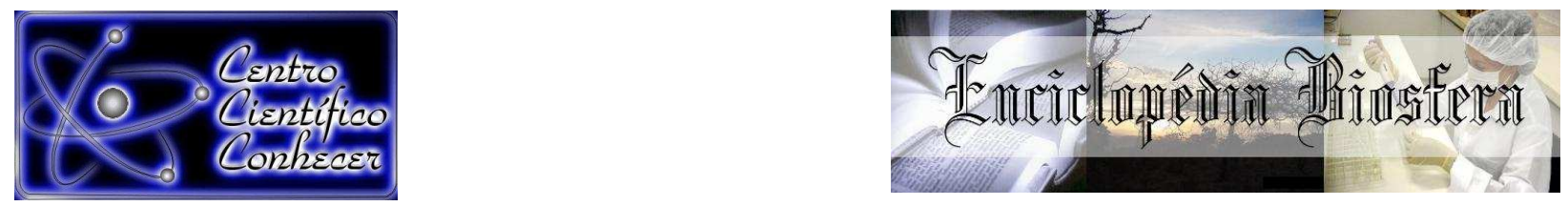

\title{
PLUVIOMETRIA DA BACIA DO RIO SÃO MIGUEL, MINAS GERAIS, BRASIL
}

Sidney Geraldo Silveira Velloso', Dionei Lima Santos², José Geraldo de Araújo Ferreira Filho ${ }^{3}$

1 Engenheiro Florestal, Mestrando do Programa de Pós-Graduação em Ciência Florestal da Universidade Federal de Viçosa, Viçosa/MG, Brasil sidney.velloso@hotmail.com

2 Engenheiro Agrônomo, Mestrando do Programa de Pós-Graduação em Engenharia Agrícola da Universidade Federal de Viçosa

3 Engenheiro Agrícola, Mestrando do Programa de Pós-Graduação em Engenharia Agrícola da Universidade Federal de Viçosa

Recebido em: 08/09/2015 - Aprovado em: 14/11/2015 - Publicado em: 01/12/2015 DOI: http://dx.doi.org/10.18677/Enciclopedia_Biosfera_2015_209

O ciclo hidrológico consiste no movimento de água no planeta, numa sequência fechada de fenômenos naturais. $O$ estoque de água continental se dá pelo balanço entre precipitação e escoamento total, portanto, uma parcela de relativo interesse para o desenvolvimento humano é a precipitação na forma líquida. A medição da precipitação é feita a partir de instrumentos instalados nas estações meteorológicas, sendo que falhas nas séries de dados observadas são comumente encontradas. Outro fator importante relacionado ao fenômeno da precipitação é a sua distribuição espacial. Assim, o objetivo do presente estudo foi avaliar o preenchimento de falhas por meio dos métodos de ponderação regional, regressão linear e ponderação regional com base em regressões lineares, bem como proceder ao cálculo da precipitação média para a bacia por meio dos polígonos de Thiessen e Isoietas. Dentre os métodos de preenchimento de falhas, aquele que apresentou menor desvio médio relativo foi o método de ponderação regional com base em regressões lineares, indicando assim, maior acurácia. Os valores de precipitação média para a bacia, calculados por meio de polígonos de Thiessen e Isoietas, apresentaram valores aproximadamente iguais, com o método de Isoietas apresentando valores ligeiramente maiores.

PALAVRAS-CHAVE: Isoietas, precipitação, preenchimento de falhas

\section{PLUVIOMETRY OF SÃO MIGUEL RIVER BASIN, MINAS GERAIS, BRAZIL}

\begin{abstract}
The hydrological cycle consists of water movement in planet, in a closed sequence of natural phenomena. The continental water stock is given by the water balance between rainfall and full flow of water, therefore, a portion of interest for human development is the precipitation in liquid form. The precipitation measurement is made by instruments installed into weather stations, and gaps in observed data series are commonly found. Another important fact related to precipitation phenomenon is its spatial distribution. Thus, the objective of this study was to evaluate the gaps filling by regional weighing, linear regression and regional
\end{abstract}


weighing based on linear regression methods, as well as proceed to the calculation of the average rainfall for the basin through Thiessen polygons and Isohyets. Among gap filling methods, the one that presented the lowest relative average deviation was the regional weighing based on linear regression method, indicating so, higher accuracy. The average rainfall values for the basin, calculated by Thiessen polygons and Isohyets, showed approximately equal values, with the Isohyets method showing slightly higher values.

KEYWORDS: Isohyets, precipitation, gaps filling

\section{INTRODUÇÃO}

O ciclo hidrológico corresponde ao movimento de água no planeta e suas mudanças de estado, numa sequência fechada de fenômenos naturais, através dos quais a água circula entre os compartimentos do meio (QUEIROZ \& OLIVEIRA, 2013). O estoque de água continental é resultante do balanço da precipitação e evaporação e escoamento total (GUEDES et al., 2013). Portanto, uma parcela deste ciclo, de relativo interesse para o desenvolvimento humano, é a precipitação na forma líquida. A magnitude e frequência da ocorrência deste tipo de precipitação dita a forma como o homem interferirá no meio, por exemplo, ao decidir pela construção de determinada obra hidráulica ou irrigação de determinada cultura.

A precipitação em regiões tropicais ocorre de maneira irregular, sendo que em determinadas localidades há a formação de duas estações climáticas distintas ao longo do ano, as chamadas estações seca e úmida (WANDERLEY et al., 2012), que, dependendo da magnitude com que ocorrem (extremos de seca ou de precipitação), podem trazer prejuízos às atividades e recursos humanos. Com isso, tornou-se de grande importância a constante mensuração do total precipitado e a forma de tratamento dos dados observados.

Para medição e coleta de variáveis de precipitação, em nível terrestre são utilizados equipamentos denominados pluviômetros e pluviógrafos, instalados em estações meteorológicas. O primeiro quantifica o total precipitado em determinada chuva, enquanto o segundo registra a variação de intensidade que houve na mesma. Visto que a coleta das informações transferidas a partir dos instrumentos supracitados é feita por intermédio de um funcionário operador da estação meteorológica, TEEGAVARAPU \& CHANDRAMOULI (2005) enfatizaram que a recorrência de falhas nas séries de dados obtidos a partir destes instrumentos é elevada, onde, muitas vezes sua utilização chega a ser inviabilizada (OLIVEIRA et al., 2010). Sendo assim, vários métodos para correção dos dados de séries históricas de precipitação são utilizados (CHIBANA et al., 2005), onde, segundo ZEILHOFER et al. (2003) deve-se escolher pares de pontos com correlação máxima entre estações e, assim proceder ao preenchimento das falhas. Vale ressaltar que as séries históricas de precipitação são disponibilizadas pelo Portal HidroWeb (www.hidroweb.ana.gov.br) da Agência Nacional de Águas (ANA).

Outro fator importante relacionado ao fenômeno da precipitação diz respeito à distribuição geográfica. A dependência espacial da distribuição da precipitação é acessada a partir de métodos de interpolação, como polígonos de Thiessen, curvas de mesma precipitação (Isoietas) e Inverso Ponderado da Distância (IDW). Nestes métodos, utilizam-se as estações meteorológicas como pontos a partir dos quais haverá a extrapolação do valor de precipitação para área total. Para aplicação de tais métodos, Sistemas de Informações Geográficas (SIG) tem sido de fundamental 
importância, uma vez que permitem a análise de grande volume de dados em tempo reduzido (BURROUGH \& MCDONNELL, 1998).

Diante do exposto, o objetivo do presente trabalho foi avaliar o preenchimento de falhas na série histórica da estação meteorológica de Arcos (02045010), a partir das metodologias de ponderação regional, regressão linear e ponderação regional com base em regressões lineares, a partir de 5 estações circundantes à estação sob investigação. Além disso, foram obtidos os valores médios de precipitação para a bacia em estudo a partir do método das Isoietas, geradas pelo método de interpolação IDW, e dos polígonos de Thiessen.

\section{MATERIAL E MÉTODOS}

O presente estudo foi realizado na bacia do Rio São Miguel, localizada a sudoeste do estado de Minas Gerais, na região do Alto São Francisco. Abrangendo parte dos municípios de Arcos e Pains, a bacia do Rio São Miguel apresenta área total de aproximadamente $296 \mathrm{~km}^{2}$. A estação pluviométrica utilizada para preenchimento de falhas foi a estação ARCOS (COPASA) de número 02045010, operada pela Companhia de Pesquisa de Recursos Minerais (CPRM). Foi estabelecido um buffer de aproximadamente $45 \mathrm{~km}$ ao redor desta estação, afim de selecionar aquelas que possuíssem uma série histórica de dados com pelo menos 30 anos. As estações selecionadas foram utilizadas como estações de apoio para os métodos de preenchimento de falhas. A figura 1 ilustra a região de estudo e destaca a distribuição espacial das 5 estações de apoio, bem como a localização da estação ARCOS (COPASA).
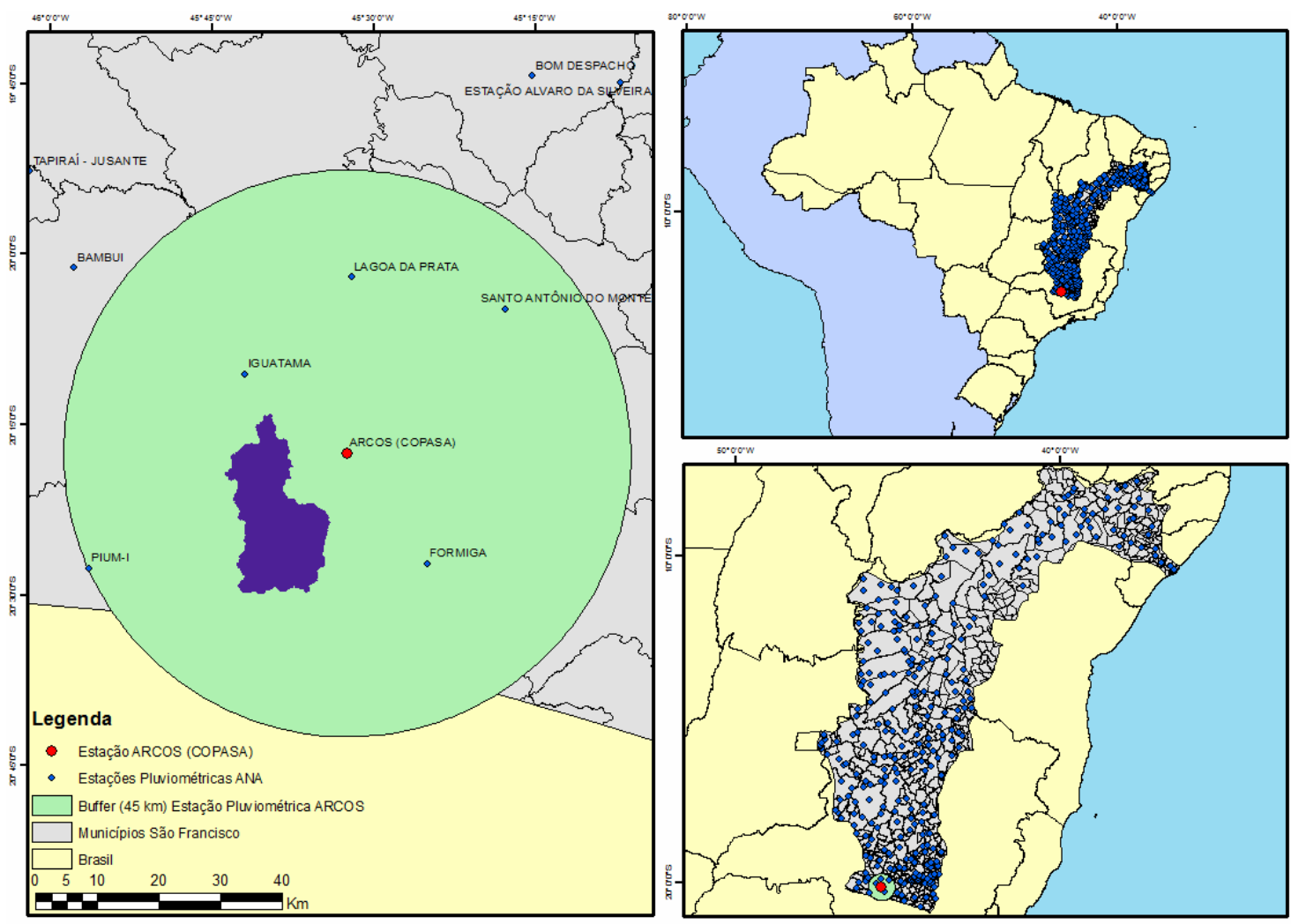

FIGURA 1: Área de estudo, com destaque para a bacia do Rio São Miguel e as estações ARCOS (COPASA), LAGOA DA PRATA, SANTO ANTÔNIO DO MONTE, IGUATAMA, PIUMI E FORMIGA. 
Os métodos de preenchimento de falhas, dos totais anuais precipitados, adotados no presente estudo foram ponderação regional, regressão linear e regressão linear com base em ponderações regionais, sendo as equações para os métodos de ponderação regional e regressão linear com base em ponderações regionais $P_{y}=\frac{1}{n}\left(\sum_{i=1}^{n} \frac{N_{y}}{N_{i}} * P_{i}\right), \quad P_{y}=\sum_{i=1}^{n} \frac{P_{i} * r_{y i}}{r_{y i}}$, respectivamente, onde $P_{y}$ é a precipitação na estação em estudo, $N_{y}$ normal da estação em estudo, $P_{i}$ precipitação na estação de apoio $i, N_{i}$ normal na estação de apoio $i, n$ número de estações de apoio e $r_{y i}$ coeficiente de correlação entre os dados da estação de apoio $i$ e da estação de estudo. O método de preenchimento de falhas por regressão linear consiste no ajuste de uma equação de regressão entre a estação de estudo e cada estação de apoio, sendo utilizada a equação que apresentar maior coeficiente de determinação $\left(R^{2}\right)$, para proceder ao preenchimento, desde que o $R^{2}$ seja $>0,7 \mathrm{e}$ que hajam no mínimo 8 pares de valores entre as estações.

As análises espaciais da distribuição da precipitação foram realizadas pelo software ArcMap 10.2.2. Foram obtidos os polígonos de Thiessen para a área da bacia, sendo os polígonos traçados em volta dos pontos representativos das estações. O cálculo da precipitação média para a bacia em estudo, a partir dos polígonos de Thiessen, se deu por $P_{m}=\sum \frac{P_{i} * A_{i}}{A_{i}}$, onde $P_{m}$ precipitação média na bacia e $A_{i}$ área de influência da estação $i$. Pelo método das Isoietas, foram traçadas curvas de nível com mesmo total precipitado, sendo que, diferentemente às curvas de nível tradicionais, no traçado das Isoietas devem ser considerados aspectos como relevo e vegetação indicativa local. No presente estudo, adotou-se o mapa de precipitação gerado a partir do método IDW para construção de tais curvas. $O$ cálculo da precipitação média por este método se deu por $P_{m}=\frac{\sum_{i=1}^{n} A_{i, i+1}\left(\frac{P_{i}+P_{i+1}}{z}\right)}{A}$, onde $A_{i, i+1}$ área compreendida entre duas Isoietas consecutivas, $P_{i}$ precipitação referente à Isoieta de ordem $i, P_{i+1}$ precipitação referente à Isoieta de ordem $i+1 \mathrm{e}$ $A$ área da bacia.

\section{RESULTADOS E DISCUSSÃO}

A série histórica, do total anual precipitado, na estação ARCOS (COPASA) apresentou falhas nos períodos 1979/1980, 1980/1981, 1989/1990, 1990/1991 e 1991/1992. A tabela 1, apresentada a seguir, indica os valores encontrados para o preenchimento de falhas pelos métodos propostos no presente estudo.

TABELA 1: Valores obtidos pelos métodos de preenchimento de falhas Ponderação regional, Regressão linear e Ponderação regional com base em regressões lineares, para os períodos de falha na estação ARCOS (COPASA).

\begin{tabular}{cccc}
\hline \multirow{2}{*}{ Período } & \multicolumn{3}{c}{ Valor preenchido (mm) } \\
\cline { 2 - 4 } & $\begin{array}{c}\text { Ponderação } \\
\text { regional }\end{array}$ & $\begin{array}{c}\text { Regressão } \\
\text { linear }\end{array}$ & $\begin{array}{c}\text { Ponderação regional com base } \\
\text { em regressões lineares }\end{array}$ \\
\hline $\mathbf{1 9 7 9 / 1 9 8 0}$ & 1420,93 & 1540,09 & 1521,03 \\
$\mathbf{1 9 8 0 / 1 9 8 1}$ & 1004,67 & 1083,53 & 1054,83 \\
$\mathbf{1 9 8 9 / 1 9 9 0}$ & 1238,94 & 1284,75 & 1322,02 \\
$\mathbf{1 9 9 0 / 1 9 9 1}$ & 1234,96 & 1068,66 & 1274,58 \\
$\mathbf{1 9 9 1 / 1 9 9 2}$ & 1647,24 & 1746,31 & 1722,74 \\
\hline
\end{tabular}


Percebe-se certa proximidade entre os valores encontrados para os três métodos avaliados no presente estudo. Para comparação entre os métodos adotados, comparou-se o valor estimado para o período ao valor da estação IGUATAMA, por esta apresentar valores observados em todos os anos em que ocorreram falhas para a estação ARCOS (COPASA). Os desvios médios relativos encontrados para os métodos de ponderação regional, regressão linear e ponderação regional com base em regressões lineares foram 253,8 mm, 271,31 mm e 214,48 mm, indicando, portanto, que a maior acurácia obtém-se pelo uso do terceiro método. OLIVEIRA et al. (2010), ao compararem metodologias de preenchimento de falhas pelo uso de seis estações, no estado de Goiás, encontraram, também pelo cálculo do desvio médio e, para os métodos utilizados no presente trabalho, maior acurácia pelo método da regressão linear e, menor acurácia pelo método da ponderação regional com base em regressões lineares. QUINTO et al. (2014), utilizaram a ponderação regional para o preenchimento de falhas nas séries históricas de dados de estações pluviométricas operadas pela ANA, no estado do Espírito Santo, tais resultados demonstram a variação que pode ser encontrada pelos métodos de preenchimento de falhas, em função da base de dados que se utiliza.

A distribuição dos polígonos de Thiessen na bacia em estudo é apresentada na figura 2. Nota-se a maior área de influência da estação ARCOS (COPASA), sendo que as estações SANTO ANTÔNIO DO MONTE e LAGOA DA PRATA não apresentaram área de influência na bacia em estudo. A tabela 2 apresenta a precipitação média anual, a precipitação média do semestre mais chuvoso e a área de influência de cada estação.

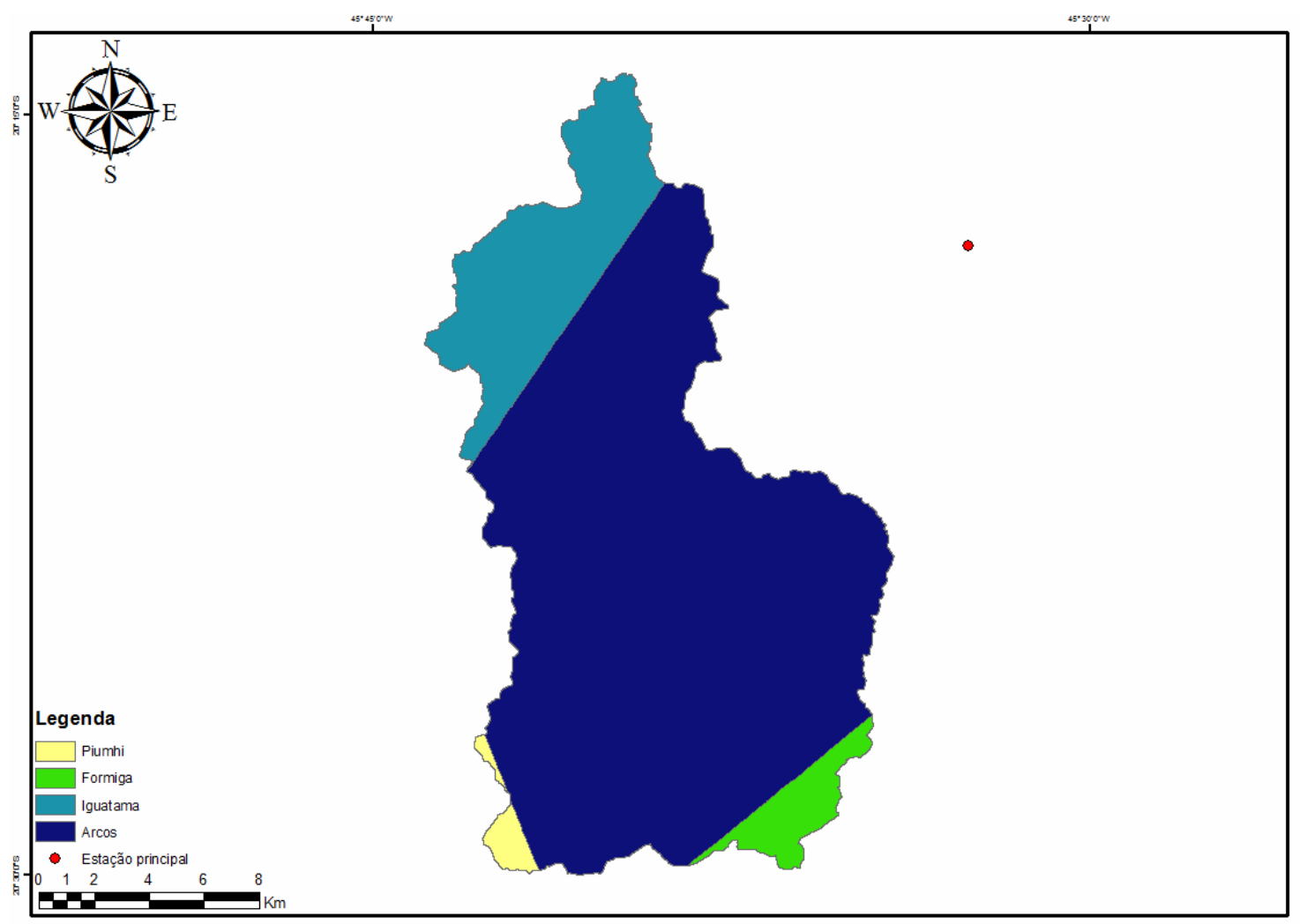

FIGURA 2: Delimitação dos polígonos de Thiessen na área da bacia em estudo, a partir das estações de apoio e da estação principal ARCOS (COPASA). 
TABELA 2: Área, Precipitação média anual e, Precipitação média do semestre mais chuvoso para as estações que apresentaram área de influência pelos polígonos de Thiessen

\begin{tabular}{cccc}
\hline Estação & Área $\left(\mathbf{k m}^{2}\right)$ & $\begin{array}{c}\text { Precipitação } \\
\text { média anual }(\mathbf{m m})\end{array}$ & $\begin{array}{c}\text { Média do } \\
\text { semestre mais } \\
\text { chuvoso }(\mathbf{m m})\end{array}$ \\
\hline $\begin{array}{c}\text { Arcos } \\
\text { Iguatama }\end{array}$ & 227,19 & 1357,9 & 1139,8 \\
Formiga & 44,8 & 1331,6 & 1118 \\
Piumhi & 10,2 & 1417,9 & 1177,1 \\
\hline
\end{tabular}

Os mapas gerados pelo método de interpolação Inverso da Distância Ponderada (IDW), para média do total anual precipitado e, média de precipitação do semestre mais chuvoso, são apresentados nas figuras 3 e 4 , respectivamente. As curvas constantes em tais figuras são as Isoietas traçadas a partir de tais mapas. A tabela 3 apresenta os valores de precipitação apresentados pelas Isoietas, bem como a área compreendida e média de precipitação entre Isoietas consecutivas.

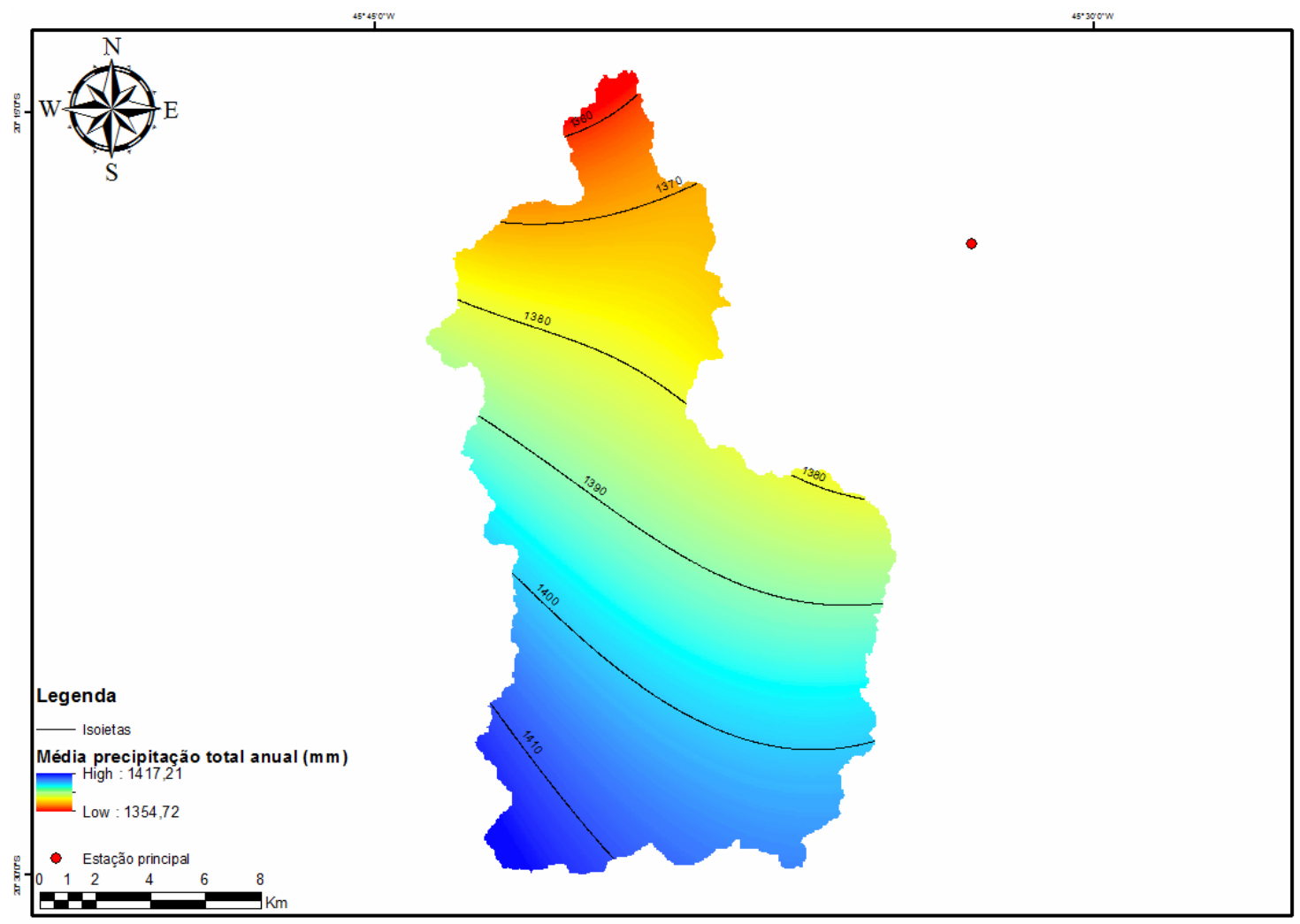

FIGURA 3: Mapa de precipitação gerado a partir do interpolador IDW e curvas de mesma média de precipitação total anual. 


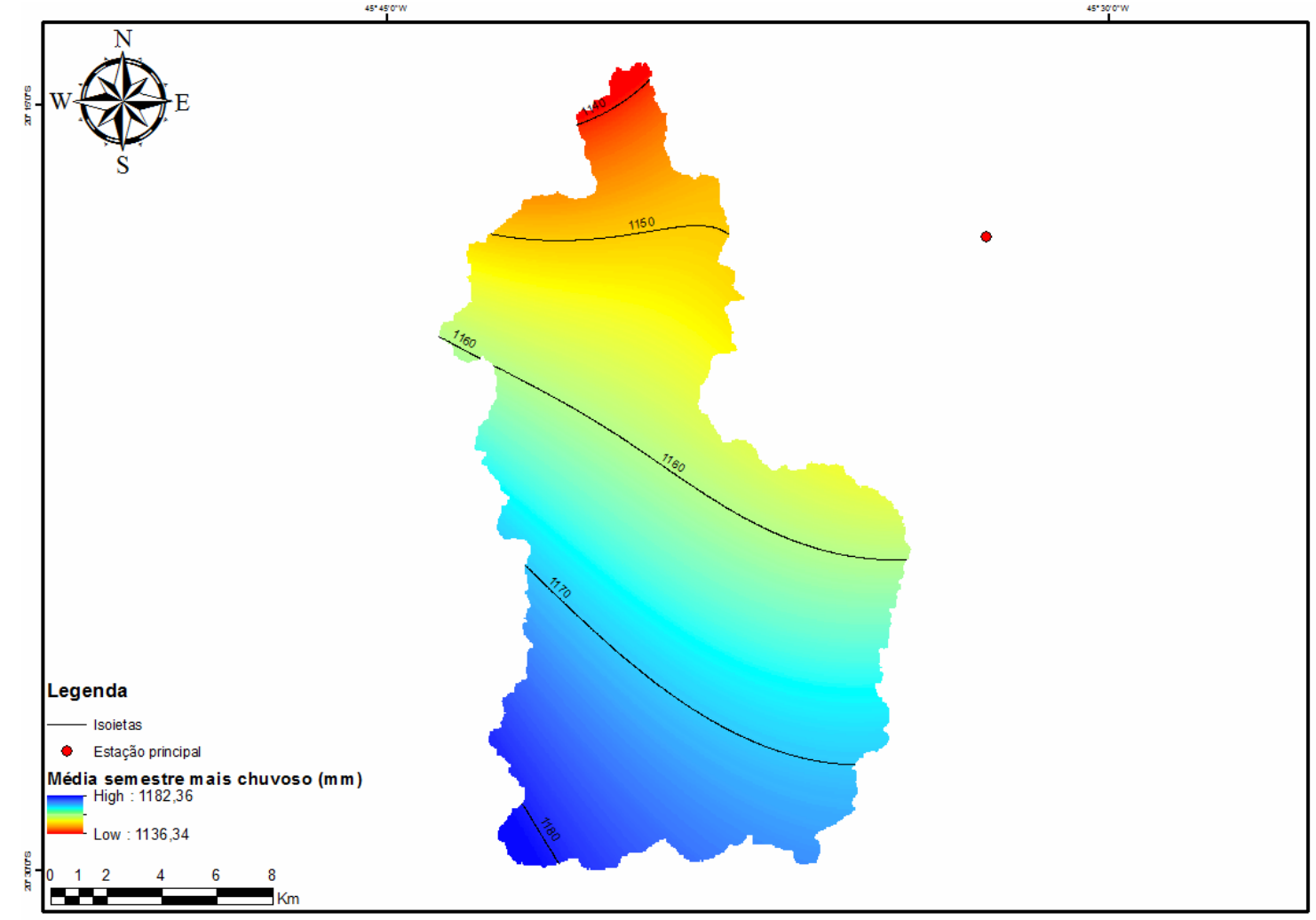

FIGURA 4: Mapa de precipitação gerado a partir do interpolador IDW e curvas de mesma média de precipitação do semestre mais chuvoso.

TABELA 3: Área e média de precipitação compreendida entre duas Isoietas consecutivas para precipitação total anual e do semestre mais chuvoso para a bacia do Rio São Miguel.

\begin{tabular}{ccc|ccc}
\hline & Total Anual & \multicolumn{3}{c}{ Semestre mais Chuvoso } \\
\hline Isoieta & Área $\left(\mathbf{k m}^{2}\right)$ & $\begin{array}{c}\text { Média } \\
\text { Precipitação } \\
(\mathbf{m m})\end{array}$ & Isoieta & Área $\left(\mathbf{k m}^{2}\right)$ & $\begin{array}{c}\text { Média } \\
\text { Precipitação } \\
(\mathbf{m m})\end{array}$ \\
\hline $\mathbf{1 4 2 0}$ & - & - & $\mathbf{1 1 9 0}$ & - & - \\
$\mathbf{1 4 1 0}$ & 13,12 & 1415 & $\mathbf{1 1 8 0}$ & 2,72 & 1185 \\
$\mathbf{1 4 0 0}$ & 62,74 & 1405 & $\mathbf{1 1 7 0}$ & 70,3 & 1175 \\
$\mathbf{1 3 9 0}$ & 76,1 & 1395 & $\mathbf{1 1 6 0}$ & 108,08 & 1165 \\
$\mathbf{1 3 8 0}$ & 72,87 & 1385 & $\mathbf{1 1 5 0}$ & 80,71 & 1155 \\
$\mathbf{1 3 7 0}$ & 45,68 & 1375 & $\mathbf{1 1 4 0}$ & 21,76 & 1145 \\
$\mathbf{1 3 6 0}$ & 12,46 & 1365 & $\mathbf{1 1 3 0}$ & 2,03 & 1135 \\
$\mathbf{1 3 5 0}$ & 2,6 & 1355 & - & - & - \\
\hline Total & 285,57 & 9695 & Total & 285,6 & 6960 \\
\hline
\end{tabular}

A tabela 4 apresenta os valores obtidos para precipitação média total anual e precipitação média total do semestre mais chuvoso pelos métodos de polígonos de Thiessen e Isoietas. 
TABELA 4: Precipitação média total anual e precipitação média do semestre mais chuvoso obtidas pelos métodos de polígonos de Thiessen e Isoietas para a bacia do Rio São Miguel.

\begin{tabular}{ccc}
\hline Método & $\begin{array}{c}\text { Precipitação Média } \\
\text { Total Anual }(\mathbf{m m})\end{array}$ & $\begin{array}{c}\text { Precipitação Média do } \\
\text { Semestre Mais Chuvoso } \\
(\mathbf{m m})\end{array}$ \\
\hline $\begin{array}{c}\text { Polígonos de Thiessen } \\
\text { Isoietas }\end{array}$ & 1357,41 & 1141,84 \\
1390,7 & 1163,1 \\
\hline
\end{tabular}

Percebe-se, pela tabela 4, que os resultados apresentados pelos métodos de polígonos de Thiessen e Isoietas, para precipitação média total anual e do semestre mais chuvoso, para a bacia do Rio São Miguel, se mostraram aproximadamente iguais, sendo que o método das Isoietas tende a apresentar valores ligeiramente maiores. MARCUZZO et al. (2011), ao analisarem Isoietas geradas pelo método IDW, destacam que uma característica inerente ao método é a geração de "ilhas" no entorno dos pontos a partir dos quais se procederá a interpolação. A presença das mesmas, está relacionada à potência que se utiliza no denominador da equação de interpolação adotada pelo IDW, bem como à distância relativa à fonte pontual de dados. MACÊDO et al. (2013), ao estudarem a precipitação pluviométrica e vazão da bacia hidrográfica do Riozinho do Rôla, utilizaram para cálculo da precipitação média, o método de polígonos de Thiessen, a partir de nove estações instaladas na bacia supra mencionada.

\section{CONCLUSÕES}

Os métodos de preenchimento de falhas propostos no presente trabalho apresentaram valores semelhantes, sendo que, pela análise do desvio médio relativo, aquele que apresentou maior acurácia foi o método de ponderação regional com base em regressões lineares. Os métodos de análise da distribuição da precipitação, polígonos de Thiessen e Isoietas, apresentaram valores similares de precipitação média total anual e precipitação média do semestre mais chuvoso para a bacia do Rio São Miguel, com o método das Isoietas apresentando valores ligeiramente maiores.

\section{REFERÊNCIAS}

BURROUGH, P. A.; MCDONNELL, R. A. Principles of GIS. Oxford University Press: London, 1998.

CHIBANA, E. Y.; FLUMIGNAN, D.; MOTA, R. G.; VIEIRA, A. S.; FARIA, R. T. Estimativa de falhas em dados meteorológicos. In: Congresso Brasileiro de Agroinformática, 9. Londrina, 2005.

GUEDES, A. E. D. S.; CÂNDIDO, L. A.; SANTO, A. R. S. E. Variabilidade do estoque de água continental e sua relação com as cheias e vazantes extremas na Amazônia. Ambi-Água, v. 8, n. 2, p. 88-89, 2013.

MACÊDO, M. N. C.; DIAS, H. C. T.; COELHO, F. M. G.; ARAÚJO, E. A.; SOUZA, M. L. H.; SILVA, E. Precipitação pluviométrica e vazão da bacia hidrográfica do Riozinho do Rôla, Amazônia Ocidental. Ambi-Água, v. 8, n. 1, p. 206-221, 2013. 
MARCUZZO, F. F. N.; ANDRADE, L. R.; MELO, D. C. R. Métodos de interpolação matemática no mapeamento de chuvas do Estado do Mato Grosso. Revista Brasileira de Geografia Física, v. 4, p. 793-804, 2011.

OLIVEIRA, L. F. C.; FIOREZE, A. P.; MEDEIROS A. M. M.; SILVA, M. A. S. Comparação de metodologias de preenchimento de falhas de séries históricas de precipitação pluvial anual. Revista Brasileira de Engenharia Agrícola e Ambiental, v. 14, n. 11, p. 1186-1192, 2010.

QUEIROZ, A. T.; OLIVEIRA, L. A. Relação entre produção e demanda hídrica na bacia do Rio Uberabinha, estado de Minas Gerais, Brasil. Soc. \& Nat., v. 25, n. 1, p. 191-204, 2013.

QUINTO, V. M.; LIMA, J. S. S.; FIEDLER, N. C.; THULER, L. H. M. Análise espaçotemporal do potencial erosivo anual da chuva no Estado do Espírito Santo. Revista Verde de Agroecologia e Desenvolvimento Sustentável, v. 8, n. 4, p. 189-196, 2013.

TEEGAVARAPU, R. S. V.; CHANDRAMOULI, V. Improved weighting methods, deterministic and stochastic data-driven models for estimation of missing precipitation records. Journal of Hydrology, v. 312, n. 191-206, 2006.

WANDERLEY, H. S.; AMORIM, R. F. C.; CARVALHO, F. O. Variabilidade espacial e preenchimento de falhas de dados pluviométricos para o estado de Alagoas. Revista Brasileira de Meteorologia, v. 27, n. 3, p. 347-354, 2012.

ZEILHOFER, P.; LIMA, E. B. R.; SANTOS, F. M.; RIGO JÚNIOR, L. O. Um ambiente SIG para modelagem integrada da qualidade da água utilizando Qual2e. Caminhos de Geografia, v. 8, n. 10, p. 107-125, 2003. 